Araştırma Makalesi - Research Article

\title{
Bir Bisiklet Gövdesinin Sonlu Elemanlar Yöntemiyle Statik Analizi
}

\author{
Mehmet ERDEM ${ }^{1 *}$, Kadir GÖK ${ }^{2}$, Mert TÜMSEK $^{3}$, Arif GÖK ${ }^{4}$ \\ Geliş / Received: 18/11/2019 \\ Revize / Revised: 01/12/2019 \\ Kabul / Accepted: 20/12/2019
}

ÖZ

Bisiklet gövdesi, tüm parçaları bir araya getiren birleştirici unsurdur. Bir bisiklet gövdesinde bulunması gereken en önemli iki özellik düşük ağırlığa ve yüksek dayanıma sahip olmasıdır. Ancak gövde dayanımını birçok faktör belirler. Bu çalışmada tasarlanan bir bisiklet gövdesinin uygulanan kuvvetlere bağlı olarak statik analizi yapılmış ve güvenilirliği araştırılmıştır. Çalışmada bisiklet gövdesinin 3 boyutlu geometrik modeli, diğer bisiklet gövdelerinden özgün olarak bilgisayar destekli tasarım programı olan SolidWorks yardımıyla gerçekleştirilmiştir. Gövde tasarımında dayanım ve kolay şekillendirilebilirlik özelliklerine sahip olan Al 6061 malzemesi seçilmiştir. Çocuk kullanıcılar için tasarlanan bisiklete $50 \mathrm{~kg}$ ağırlığında bir sürücünün bindiği varsayılmıştır. Sisteme etki eden kuvvetlere bağlı olarak gövdenin statik analizinde Sonlu Elemanlar Yöntemi (SEM) kullanılmıştır. Yapılan analiz sonucu gövde üzerinde Von Misses gerilme değeri 16.3 MPa olarak hesaplanmıştır. Kullanılan malzemenin akma sınırının 55.1 MPa olduğu dikkate alındığında, tasarlanan bisiklet gövdesinin uygulanan kuvvetler altında 3.38 kat emniyetli olduğu ortaya çıkmış ve sonuçların doğruluğu ispatlanmıştır.

\section{Anahtar Kelimeler- Gövde, Kuvvet, Sonlu Elemanlar Yöntemi, Statik Analiz,}

\footnotetext{
1* Sorumlu yazar iletişim: mehmet.erdem@dpu.edu.tr (https://orcid.org/0000-0002-1936-1338)

Makine ve Metal Teknolojileri Bölümü, Kütahya Teknik Bilimler MYO, Kütahya Dumlupınar Üniversitesi, Kütahya, Türkiye.

2 İletişim: kadir.gok@bakircay.edu.tr (https://orcid.org/0000-0001-5736-1884)

Biyomedikal Mühendisliği Bölümü, Mühendislik ve Mimarlık Fakültesi, İzmir Bakırçay Üniversitesi, İzmir, Türkiye.

3 İletişim: mert.tumsek@hotmail.com (https://orcid.org/0000-0012-5615-7224)

Makine ve Imalat Mühendisliği anabilim Dall, Fen Bilimleri Enstitüsü, Manisa Celal Bayar Üniversitesi, Manisa, Türkiye.

4 İletişim: arif.gok@amasya.edu.tr (https://orcid.org/0000-0002-3309-6921)

Makine Mühendisliği Bölümü, Teknoloji Fakültesi, Amasya Üniversitesi, Amasya, Türkiye.
} 


\title{
Static Analysis of a Bicycle Frame by Finite Element Method
}

\begin{abstract}
The bicycle frame is the unifying element that gathers up all the parts together. The two most important features of a bicycle frame are low weight and high strength. However, many of the strength of the frame. In this study, the static analysis of the bicycle frame depending on the applied forces was performed and its reliability was investigated. In this study, the 3D geometric model of the bicycle frame was realized with the help of SolidWorks, a computer-aided design program, which is unique from other bicycle frames. Al 6061 material has been chosen which has strength and easy formability in body design. Designed for children, a $50 \mathrm{~kg}$ rider is assumed to ride the bicycle. Depending on the forces acting on the system, Finite Element Method (FEM) was used in the static analysis of the frame. As a result of the analysis, the stress value of Von Misses on the frame was calculated as 16.3 MPa. Considering that the yield limit of the material used is $55.1 \mathrm{MPa}$, the designed bicycle body has been found to be 3.38 times safe under the applied forces and the results have been proved to be accurate.
\end{abstract}

Keywords- Frame, Force, Finite Element Method, Static Analysis 


\section{GİRIŞ}

Dünya nüfusunun hızla artması birçok problemi de beraberinde getirmektedir. Çevrenin kirlenmesine sebep olan durumlardan biri olan zararlı gazlar içinde en büyük etkiyi motorlu araçlardan havaya bırakılan egzoz gazları oluşturmaktadır [1,2]. Otomobillerde yaygın olarak kullanılan içten yanmalı motorlar yakıt enerjisinin yaklaşık \%35-\%40’ını egzoz sistemi aracılığıyla doğrudan atık ısı olarak atmosfere bırakır [3, 4]. Bu sebepten gün geçtikçe ulaşım için gerekli araçlar, doğaya zarar vermeden çalışacak araç teknolojileri üzerine planlanmaktadır. $\mathrm{Bu}$ duruma zıt olarak doğaya zararı bulunmayan bisiklet kullanımını artırıcı teşvikler ile insanların bilinçlendirilmesi devam etmektedir [5-7]. Bisiklet üzerinde zaman geçirmenin fiziksel ve zihinsel olarak çok sayıda yararının olması da bu farkındalığı öne çıkarmaktadır [8]. Farklı disiplinlere ve alt branşlara sahip olan bisiklet sporu hem şehir içinde hem de arazide ve çetin doğa koşullarında yapılabilir. Bu durumda bir bisiklet sistematiğinde en önemli eleman, mekanik bileşenler ve teker setleri ile donatılmış olan gövdedir. Modern bisiklet tasarım teknolojisinde, gövde geometrileri daha çok sağlamlık ve aerodinamik kriterler 1 şı ğında yaratılmaktadır [9].

Tasarım süreci açısından incelendiğinde, gövdelerin temelde iki farklı üçgen geometrinin bir araya gelmesiyle oluştuğu görülür. Bunlardan birincisi ana üçgen diye tabir edilebilen kısım, ikincisi ise eklemlenmiş arka üçgendir. Bu nedenle bisikletin dayanımı, insan ağırlığını taşıyabilecek güçte olmasına ve gövde tasarımının uygunluğuna bağlıdır.

Liu ve $\mathrm{Wu}$ [10] çalışmalarında, karbon/epoksi kompozit laminatlardan yapılmış bisiklet gövdesi için lif yönü ve istifleme sırası tasarımını tartışmışlardır. Xiang vd. [11] bisiklet çerçevesindeki yükleri elde etmek için deney ve dinamik simülasyonu birleştirmişlerdir. Callens ve Bignonnet [12] çalışmalarında, Decathlon tarafından MKniX Mühendislik Merkezi aracılığıyla geliştirilen kaynaklı alüminyum alaşımlı bisiklet gövdesinin yorulma tasarımının metodolojisini açıklamışlardır. Xiang vd., [13] bir dağ bisikletinin arka süspansiyonunun parametrelerini esas alarak titreşime dayalı analizini ve tasarımını geçekleştirmişlerdir. Ba Hung ve Lim [14] elektrik yardımıyla çalışan bisikletin tüketim özelliklerini gerçek çalışma koşullarında incelemek amacıyla yapmış oldukları deneysel çalışmanın sonuçlarının simülasyon sonuçları ile örtüştüğünü ortaya koymuşlardır. Covill vd. [15] standart bir çelik bisiklet gövdesinin laboratuvar koşullarında ve sahada ölçülmüş çeşitli yük durumlarına karşı davranışını simüle etmek için sonlu elemanlar modeli oluşturmuşlar, elde ettikleri sonuçların literatürde sunulan simülasyonlarla benzerlik gösterdiği sonucuna varmışlardır. Şengül ve Kam, araç lastiklerinde durağan halde ve ilk hareket anında oluşan sürtünme ve titreşim etkilerini SEM ile analiz etmişlerdir [16].

Bu çalışmada özgün olarak tasarlanan bisiklet gövdesinin uygulanan yüklere karşı gösterdiği davranış, teorik hesaplamalar ve bilgisayar destekli yapısal analiz programı ile analiz edilerek güvenilir olup olmadığı araştırılmıştır.

\section{MATERYAL VE METOT}

\section{A. Tasarım}

Yapılan bu çalışmada dayanımı arttırmanın yanında rahat, konforlu ve özgün bir bisiklet tasarlanmıştır. Bu sayede, tasarlanan bisikletin daha çok tercih edilmesi sağlanacaktır. Çalışmada öncelikle bilgisayar ortamında bisiklet gövdesinin 3 boyutlu (3B) tasarımı yapılmıştır (Şekil 1). 3B tasarımda SolidWorks 2018 programından yararlanılmıştır. 


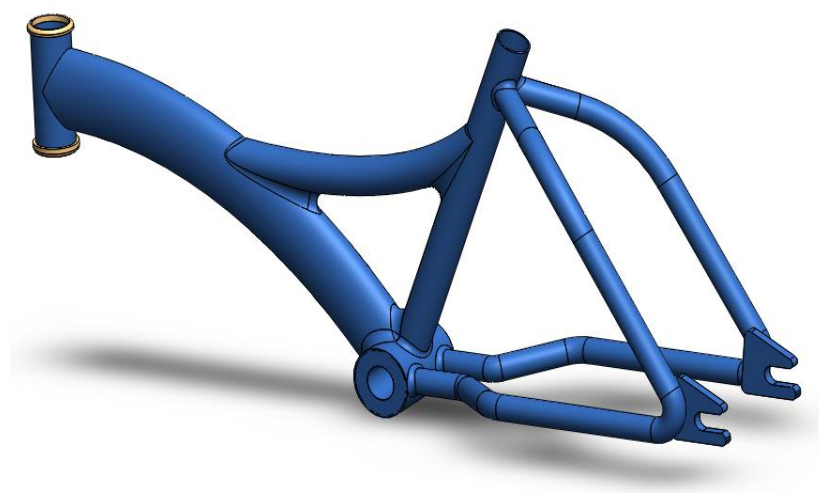

Şekil 1. Bisikletin Gövde Tasarımı

Sürücü, bisikletin üzerindeyken bisiklet gövdesine belirli yükler gelmektedir. Hareketsiz dururken bu yük sadece yukarıdan aşağıya etki eden sürücünün ağırlığıdır. Öte yandan sürücü bisikleti kullanmaya başladığında pedal hareketleriyle beraber yanal kuvvetler de etki etmeye başlar. Bu kuvvetler kişinin ağırlığına, ayakta pedal çevirip çevirmediğine, bir virajda yatıp yatmadığına, zemin koşullarına bağlı olarak artmakta ya da azalmaktadır. İki üçgenin birleşmesiyle ortaya çıkan bu gövde tasarımı, sürücünün bisiklet üzerindeyken gövdeye yüklediği kuvvetlere karşı gelen en dayanıklı tasarımdır. Özellikle ayakta pedal çevirme, bozuk zeminde sürme gibi durumlarda gövdenin sağlamlığı ve esnek bir davranış sergilemesinin önemli olduğu durumlarda bu tasarım öne çıkmaktadır.

Şekil 2'de görüldüğü gibi bisiklet direksiyonu, ön tekerleğe bağlı olup bisiklete yön veren ve iki ucundan tutulan yatay çubuktur. Kısaca yönelgeç olarak adlandırılır. Bisikletin yönlenme kabiliyeti tamamen direksiyon sayesinde sağlanır. Ayrıca her iki ucundan tutularak direksiyon üzerine belirli bir yük uygulanır.

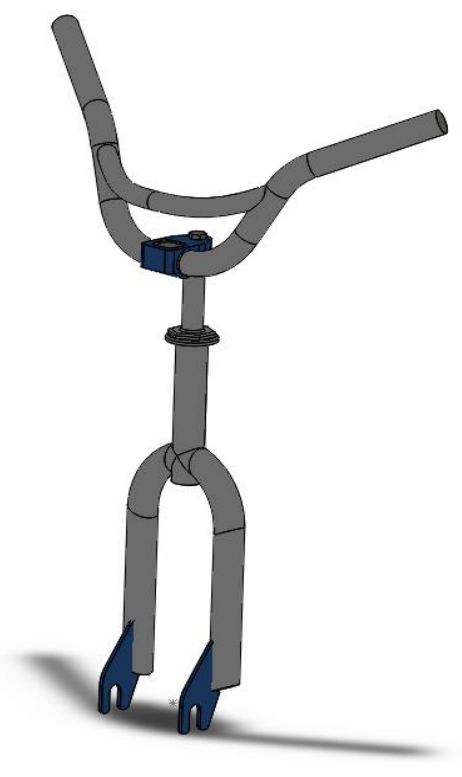

Şekil 2. Bisikletin Direksiyon Tasarım

\section{B. Bilgisayar Destekli Sonlu Elemanlar Analizi}

Yük altında çalışan makine elemanı ya da bileşenlerinde yükün türüne göre çekme, basma, eğilme, burulma ve flambaj gibi gerilmeler meydana gelir. Bu gerilmeler makine elemanı ya da bileșeninin üretildiği 
malzemenin akma dayanımını aşacak kadar yüksek ise makine elemanı ya da bileşeninde kalıcı deformasyonlar meydana gelecektir. Bu kalıcı deformasyon mukavemet hesaplamalarında istenmeyen bir durumdur. Ayrıca sistemin çalışması esnasında istenmeyen titreşim ya da balans yapmasına sebep olacaktır. Bu tür analizler bilgisayar ortamında yapısal olarak hesaplanabilmektedir. Bisiklet gövdesinin tasarımında dayanım ve kolay şekillendirilebilirlik avantajları dikkate alınarak Al 6061 malzemesi seçilmiştir. Malzeme özellikleri Tablo 1'de yer almaktadır.

Tablo1. Al 6061 Alaşımının Mekanik Özellikleri [17]

\begin{tabular}{lll}
\hline Özellik & Değer & Birim \\
\hline Elastikiyet Modülü & 69000 & $\mathrm{MPa}$ \\
Poisson Oranı & 0.33 & \\
Kayma Modülü & 26000 & $\mathrm{MPa}$ \\
Yoğunluk & 2700 & $\mathrm{~kg} / \mathrm{m}^{\wedge} 3$ \\
Çekme Dayanımı & 124.084 & $\mathrm{MPa}$ \\
Akma Dayanımı & 55.1485 & $\mathrm{MPa}$ \\
Is1l İletkenlik & 170 & $\mathrm{~W} /(\mathrm{m} \cdot \mathrm{K})$ \\
Özgül Is1 & 1300 & $\mathrm{~J} /(\mathrm{kg} \cdot \mathrm{K})$ \\
\hline
\end{tabular}

Bisiklet gövdesi Şekil 3'de gösterilen yüzeylerden seçilerek sabitlenir. Çocuklar için tasarlanan bisiklete (Şekil 4) $50 \mathrm{~kg}$ ağırlığında bir sürücünün bindiğini varsayılmıştır. Liu ve arkadaşlarının [10] yaptığı bir çalışmada, 100 kg ağırlığındaki bir kişinin bisiklet üzerindeki kuvvet dağılımı aşağıda verildiği gibidir:

Fv1 = 6 kgf, Fv2= 67 kgf ve Fv3=13.5 kgf. Toplam dikey yük 100 kgf' dir (Şekil 5).

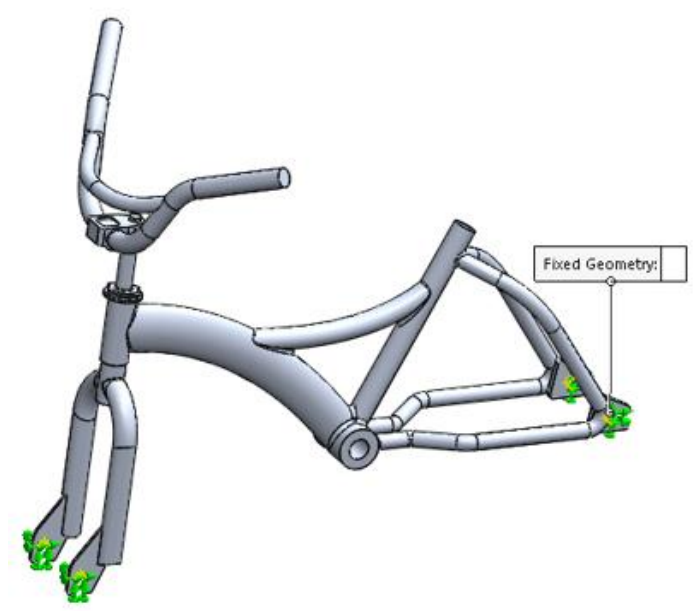

Şekil 3. Bisiklet gövdesinde sabitlenen yüzeyler 


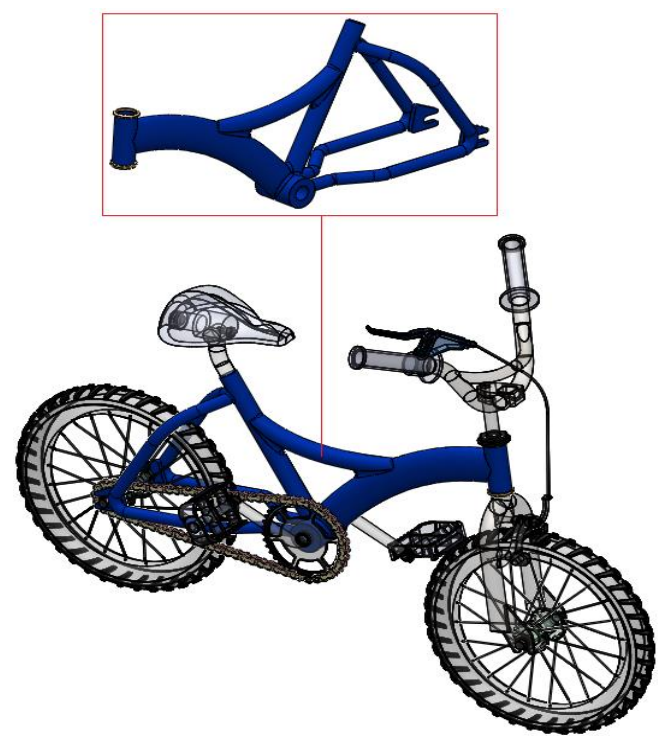

Şekil 4. Bisikletin komple montaj görünümü

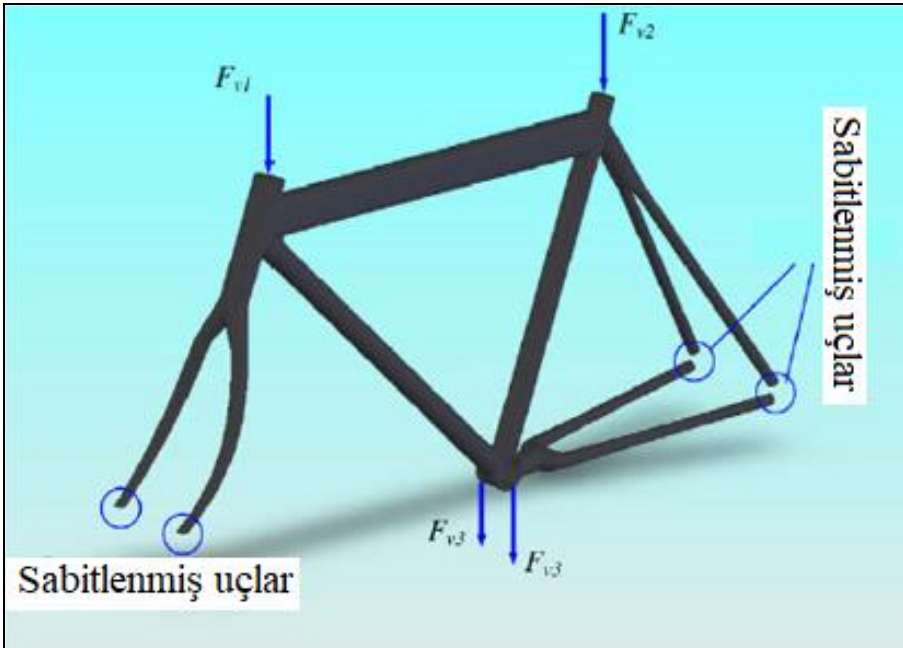

Şekil 5. Bisiklet gövdesinde oluşan yükler

Bu çalışmada, 50 kg ağırlığındaki bir çocuğun etki ettiği yük dağılımı bu değerlerin yarısı kadardır. (1N $=0,1 \mathrm{~kg}$ ) olduğu dikkate alınırsa, yük dağılımı Şekil 6' da görüldüğü gibi oluşur. Yükleme ve sınır şartları aşamasından sonra gövdeye mesh (ağ) işlemi uygulanmıştır. Ağ işlemi için üçgensel eleman tipi seçilmiştir. Sonlu eleman modelinde 96777 düğüm 55585 eleman oluşmuştur. (Şekil 7). 
BȘEÜ Fen Bilimleri Dergisi

6 (2), 605-615, 2019
BSEU Journal of Science

DOI: 10.35193/bseufbd. 648219

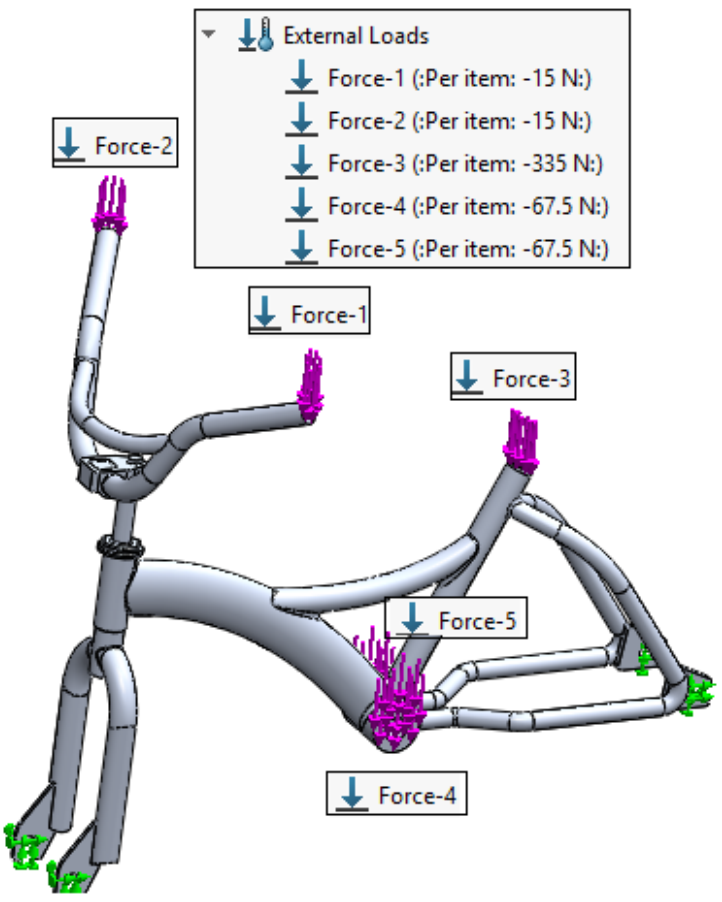

Şekil 6. 50 kg ağırlığında bir çocuğun etki ettiği yük dağılımı

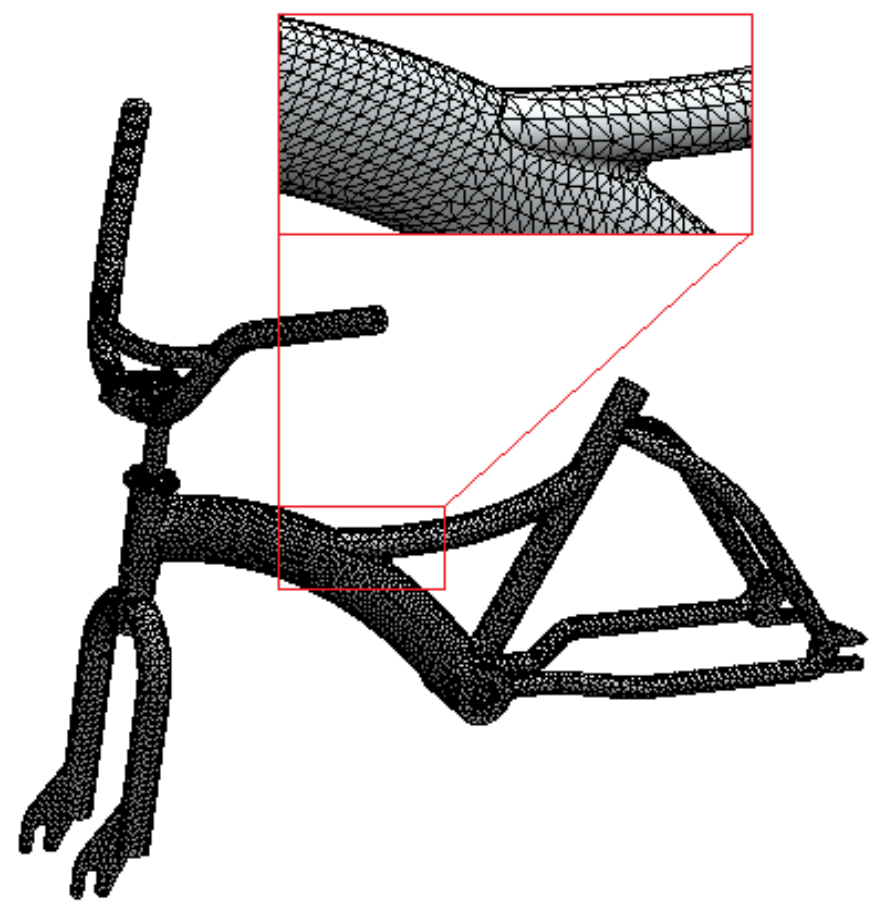

Şekil 7. Bisiklet gövdesinin ağ yapısı 


\section{SONUÇLAR VE BULGULAR}

Bisiklet gövdesinin tasarımında kullanılan Al 6061 alaşımının akma dayanımı Tablo 1'de görüldüğü gibi 55.1 MPa'dır. Yapılan analiz sonucunda gövde üzerinde oluşan Von Mises Gerilme değeri ise 16.3 MPa olarak hesaplanmıştır (Şekil 8). Bir yükün etkisi altındaki malzemede kalıcı deformasyon oluşmaması için gerilme-birim şekil değiştirme eğrisinde Elastik Deformasyon Bölgesinde kalması gerekir. Tasarım sürecinde ihtiyaç duyulan malzemenin mekanik özelliklerine ilişkin hesaplamalar bu bölgeye göre yapılır [18-20]. Şekil 9'da görüldüğü gibi malzemeye uygulanan yük kaldırıldığında eski halini alıp Elastik Deformasyon Bölgesine geri dönüyorsa malzemede herhangi bir kalıcı deformasyon oluşmaz. Bunun için yükün etkisiyle oluşan

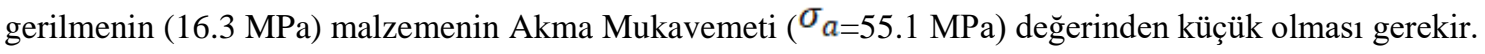

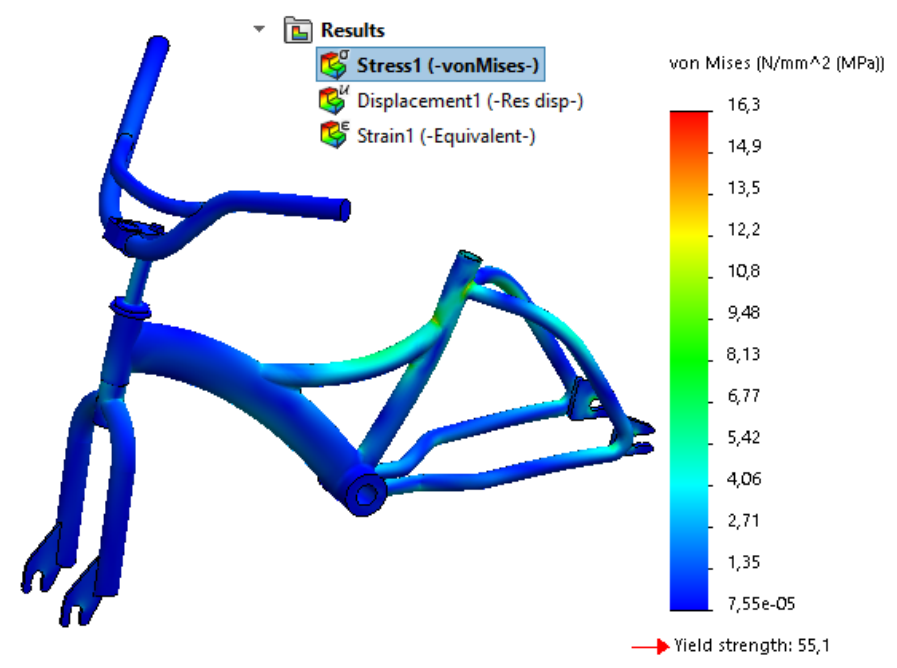

Şekil 8. Gövde üzerinde oluşan Von Mises Gerilmeleri

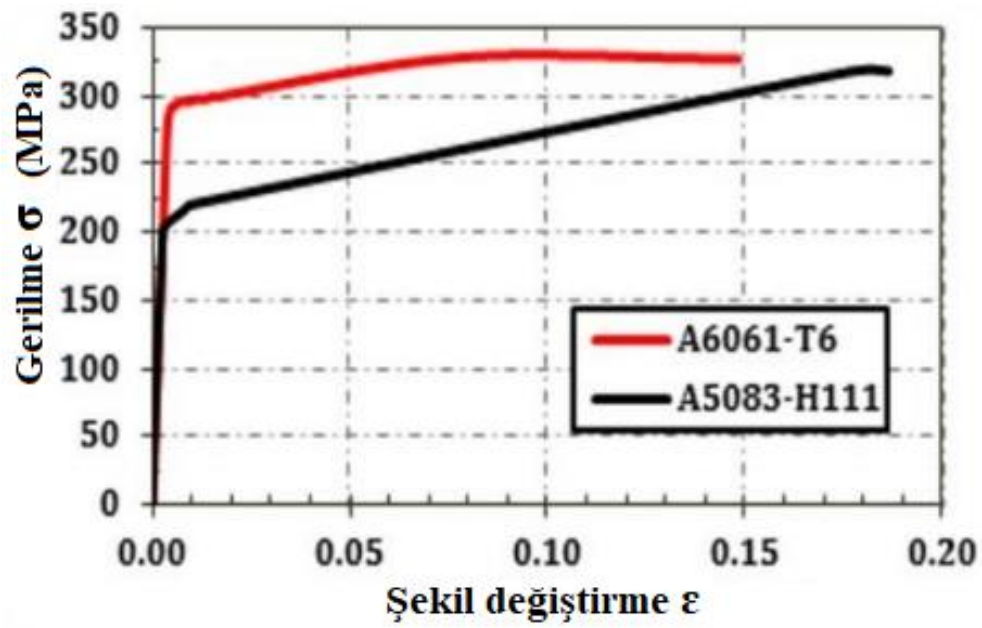

Şekil 9. Gerilme - Birim şekil değişimi eğrisi [21]

Belirli bir yük altındaki bir malzemede kalıcı deformasyon olup olmadığı araştırmak için güvenlik faktörü hesaplanmalıdır. Güvenlik faktörü, malzemenin akma dayanımının, yük altında oluşan maksimum gerilmeye oranıdır ve Denklem (1)’ de görüldüğ ü gibi hesaplanır. 
BȘEÜ Fen Bilimleri Dergisi

6 (2), 605-615, 2019
BSEU Journal of Science

DOI: 10.35193/bseufbd. 648219

Güvenlik Faktörü $=\frac{\text { Malzemenin Akma Dayanımı }}{\text { Yük Altında Meydana Gelen Maksimum Gerilme }}$

Güvenlik Faktörü $=\frac{55,1}{16,3}=3,38$

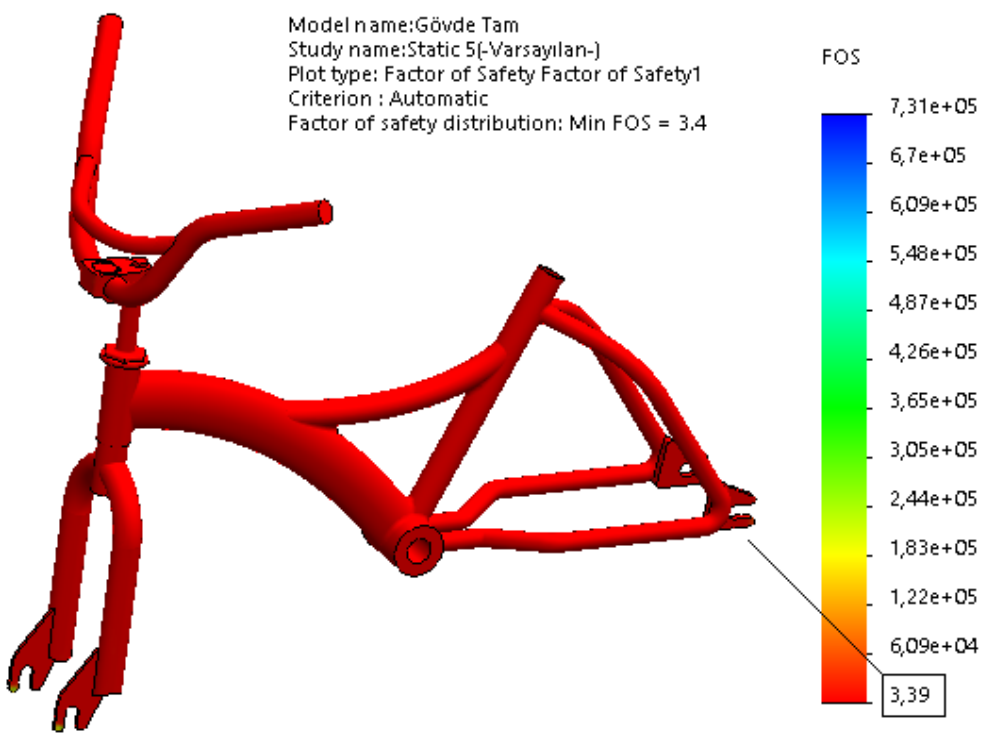

Şekil 10. Güvenlik faktörü dağılımı

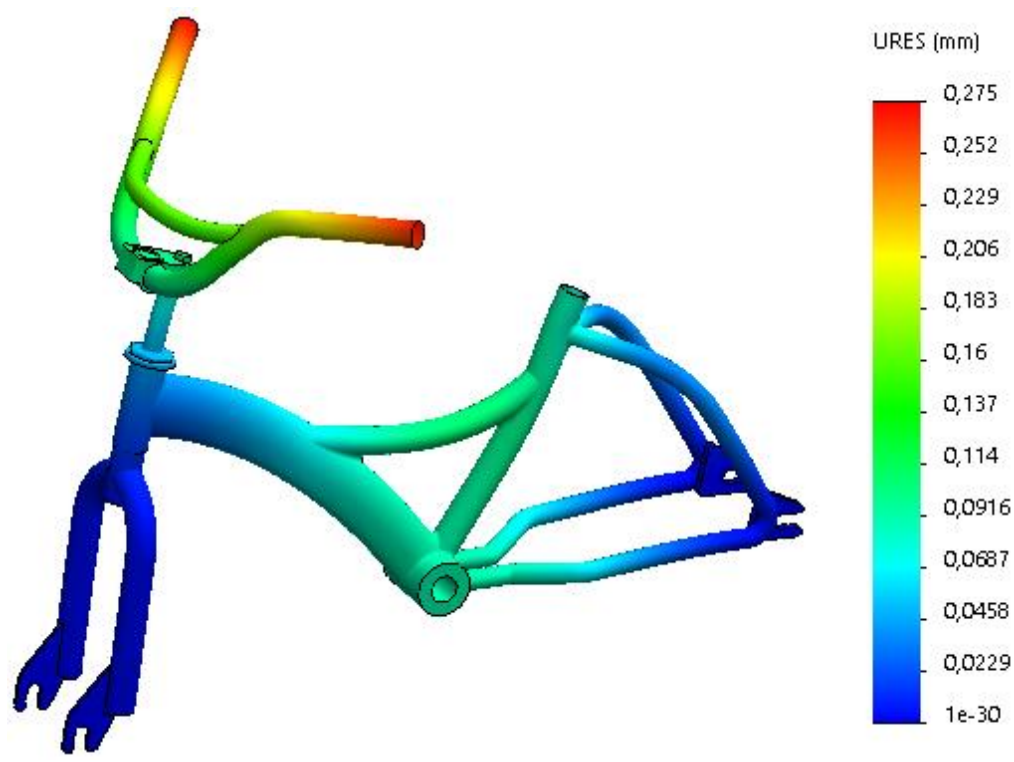

Şekil 11. Gövde üzerinde oluşan maksimum deformasyon değeri 
Güvenlik Faktörü teorik olarak 3.38 olarak hesaplanmıştır. Genelde mukavemet hesaplamalarında bu değerin 1 'in üzerinde olması istenir. Güvenlik faktörü analiz sonucunda ise 3.39 olarak hesaplanmıştır. Sonuçlar birbirine çok yakındır. Gövde üzerinde güvenlik faktörü (Şekil 10) dağılımı gösterilmiştir. Şekil 11 'de ise gövde üzerinde oluşan maksimum deformasyon değeri görülmektedir.

\section{DEĞERLENDİRME}

Bu çalışmada özgün olarak tasarlanan bisiklet gövdesine uygulanan yüklere karşı gösterdiği davranış, teorik hesaplamalar ve bilgisayar destekli yapısal analiz programı ile analiz edilmiş ve güvenilir olup olmadığ 1 araştırılmıştır. Sonuç olarak $50 \mathrm{~kg}$ ağırlığındaki bir çocuk 3,38 kat emniyetle bisiklete binebilmektedir.

\section{KAYNAKLAR}

[1] Gao, J. et al. 2018. Evaluating the cycling comfort on urban roads based on cyclists' perception of vibration. Journal of Cleaner Production, 192, 531-541.

[2] Tainio, M. et al. 2019. Can air pollution negate the health benefits of cycling and walking? Preventive Medicine, 87, 233-236.

[3] Shen, K. et al. 2019. Experimental study on the effects of exhaust heat recovery system (EHRS) on vehicle fuel economy and emissions under cold start new European driving cycle (NEDC). Energy Conversion and Management, 197, 111893.

[4] $\mathrm{Yu}, \mathrm{S}$. et al. 2015. Effect of vehicle driving conditions on the performance of thermoelectric generator. Energy Conversion and Management, 96, 363-376.

[5] Agarwal, A. Ziemke, D., and Nagel, K. 2019. Bicycle superhighway: An environmentally sustainable policy for urban transport. Transportation Research Part A: Policy and Practice.

[6] Bacchieri, G. et al. 2010. Cycling to work in Brazil: Users profile, risk behaviors, and traffic accident occurrence. Accident Analysis \& Prevention, 42(4), 1025-1030.

[7] Wilson, O. et al. 2018. Best practices for promoting cycling amongst university students and employees. Journal of Transport \& Health, 9, 234-243.

[8] Zhang, L. et al. 2015. Sustainable bike-sharing systems: characteristics and commonalities across cases in urban China. Journal of Cleaner Production, 97, 124-133.

[9] Cormier, J.-R. and LaPlante, G. 2018. Study of the effects of low-velocity impact on a composite bicycle down tube. Composite Structures, 198. 144-155.

[10] Liu, T.J.-C. and Wu, H.-C. 2010. Fiber direction and stacking sequence design for bicycle frame made of carbon/epoxy composite laminate. Materials \& Design, 31(4), 1971-1980.

[11] Xiang, Z. et al. 2011. Load on bicycle frame during cycling with different speeds and gestures. Transactions of Tianjin University, 17(4), 270-274.

[12] Callens, A. and Bignonnet, A. 2012. Fatigue design of welded bicycle frames using a multiaxial criterion. Procedia Engineering, 34, 640-645. 
[13] Xiang, Z.X. et al. 2008. Vibrant comfort-based parameterization for mountain bike rear suspension. Tianjin Daxue Xuebao (Ziran Kexue yu Gongcheng Jishu Ban)/Journal of Tianjin University Science and Technology, 41, 685-689.

[14] Ba Hung, N. and Lim, O. 2019 The effects of operating conditions and structural parameters on the dynamic, electric consumption and power generation characteristics of an electric assisted bicycle. Applied Energy, 247, 285-296.

[15] Covill, D. et al. 2016. An Assessment of Bicycle Frame Behaviour under Various Load Conditions Using Numerical Simulations. Procedia Engineering, 147, 665-670.

[16] Şengül, Ö. and Kam, M. (2019). Analysis of radial tire design and dynamic analysis for sustainable production, International Marmara Science and Social Sciences CongressIMASCON2019 Spring. Kocaeli, 1135-1142.

[17] SolidWorks Material Library

[18] Gök, K. and Gök, A. 2018. AnsysWorkbench. Abaküs Kitap, İstanbul, 367.

[19] Gürsoy, Ö.K. and Esener, E. 2019. Malzeme Modellerinin Sac Metal Sonlu Elemanlar Analizi Tahmin Performansına Etkisinin Değerlendirilmesi. Bilecik Şeyh Edebali Üniversitesi Fen Bilimleri Dergisi, 6(1), 1-11.

[20] Şengül, Ö. and Kam, M. (2019). Kapak atma rampasının sonlu elemanlar metodu ile statik analizi. International Marmara Science and Social Sciences Congress-IMASCON2019 Spring. 2019. Kocaeli, 1143-1149.

[21] Karataş, Ç.A. and Çelik, O.C. 2017. Design, fabrication, and cyclic behavior of aluminum alloy core buckling restrained braces (BRBs). Pamukkale University Journal of Engineering Sciences, 23(6), 659-670. 